\title{
Swan Song
}

\section{Donald Hantula $^{1}$ - Thomas S. Critchfield ${ }^{2}$. Erin Rasmussen ${ }^{3}$}

This is the last new issue of The Behavior Analyst that you will hold in your hands or view on a screen. The Association for Behavior Analysis International is not ceasing to produce a member-benefit flagship journal, but what you will receive starting in 2018 will be bigger, bolder, and more focused and will carry a new name: Perspectives on Behavior Science. The contingencies surrounding research, scholarship, publications, and application have changed markedly in the past decade - even more so than in the four decades since The Behavior Analyst first appeared. No discipline should regard any practice as immutable. We must adapt to a vastly different landscape.

\section{A Bit of History}

The Behavior Analyst grew out of a newsletter published by the Midwestern Association for Behavior Analysis (MABA) in 1976. In 1978, MABA first published The Behavior Analyst as a journal on a trial basis. ABA (later the Association for Behavior Analysis International [ABAI]) took over responsibility for publishing the journal with its third volume in 1980. Editors who have served the publication since its inception are listed in Table 1.

The first policy statement in Scott Wood's (1978) inaugural editorial was "The Behavior Analyst should contribute to the effective governance and functioning of MABA" (p. 1). This set the stage for the journal to function as both a newsletter and a scholarly journal, neither betwixt nor between. Articles in these early years were as likely to address practice or professional issues as scholarly issues, and as

Donald Hantula

hantula@temple.edu

1 Department of Psychology, Temple University, Weiss Hall, 1701 North 13th Street, Philadelphia, PA 19122, USA

2 Department of Psychology, Illinois State University, Normal, IL, USA

3 Department of Psychology, Idaho State University, Pocatello, ID, USA 
Table 1 Editors of The Behavior Analyst From Inception to Present

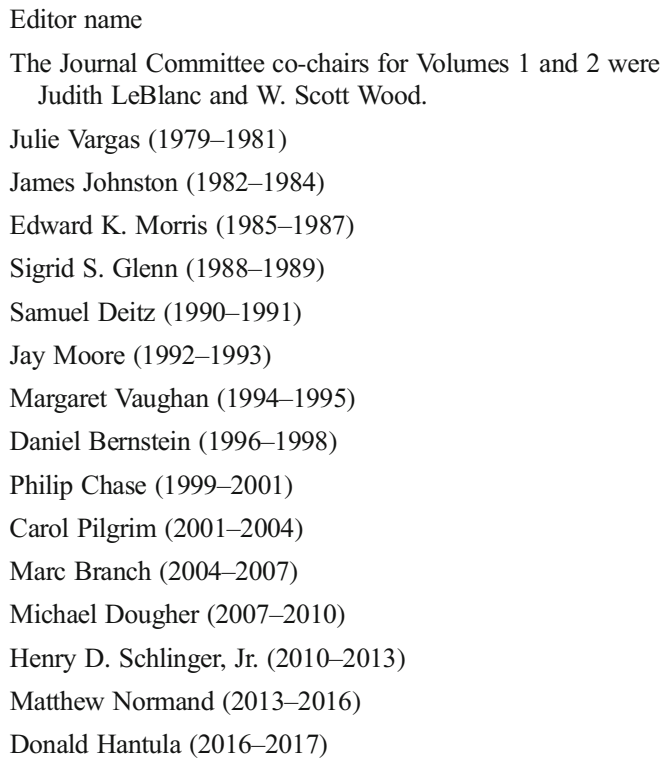

Editor name

The Journal Committee co-chairs for Volumes 1 and 2 were Judith LeBlanc and W. Scott Wood.

Julie Vargas (1979-1981)

James Johnston (1982-1984)

Edward K. Morris (1985-1987)

Sigrid S. Glenn (1988-1989)

Samuel Deitz (1990-1991)

Jay Moore (1992-1993)

Margaret Vaughan (1994-1995)

Daniel Bernstein (1996-1998)

Philip Chase (1999-2001)

Carol Pilgrim (2001-2004)

Marc Branch (2004-2007)

Michael Dougher (2007-2010)

Henry D. Schlinger, Jr. (2010-2013)

Matthew Normand (2013-2016)

Donald Hantula (2016-2017)

a result the journal has always underperformed in terms of objective metrics of influence, such as paid subscriptions, citations, and impact factor. In the beginning, these and other metrics were not important, but over the years they have become critical.

Had 1970s circumstances remained in place, perhaps The Behavior Analyst could have remained a hybrid periodical that had something for everyone - a solid scholarly paper here, a practice piece there, association announcements, some casual musings from a prominent individual or two, a few replies to previous articles, and the occasional short article "on terms." However, the movement toward "accountability" in academics and its associated flawed journal metrics discouraged submissions from many authors. Differentiation and speciation of the field (Marr, 1991, 2017; Rider, 1991) proceeded to the point where the various branches of our discipline became disconnected (Pierce \& Epling, 1980, described the trend in these very pages). The "something for everyone" journal began to mean "nothing for anyone."

\section{Differentiation within the Niche}

As interest in "behavior analysis" in general flourished, so did outlets for such work. In 1978 , only a handful of journals published behavior-analytic work. A real need and demand for rigorous scholarship in our discipline grew, and The Behavior Analyst became the home for some important behavioral scholarship. But at the same time, behavior analysis was becoming more practitioner oriented and "professionalized." Table 2 lists the 12 most highly cited articles in The Behavior Analyst according to a Google Scholar search performed in October 2017. Eleven of these articles are research-based scholarly review and theory papers that have been defining works for the field and research-based applications. Only one could be considered to be a 
Table 2 Most Highly Cited Papers in The Behavior Analyst

Citation

Binder, C. (1996). Behavioral fluency: Evolution of a new paradigm. The Behavior Analyst, 19, 163.

Cameron, J., Banko, K. M., \& Pierce, W. D. (2001). Pervasive negative effects of rewards on intrinsic motivation: The myth continues. The Behavior Analyst, 24, 1-44.

Glenn, S. S. (1988). Contingencies and metacontingencies: Toward a synthesis of behavior analysis and cultural materialism. The Behavior Analyst, 11, 161-179.

Glenn, S. S. (2004). Individual behavior, culture, and social change. The Behavior Analyst, 27, 133-151.

Hayes, S. C., \& Brownstein, A. J. (1986). Mentalism, behavior-behavior relations, and a behavior-analytic view of the purposes of science. The Behavior Analyst, 9, 175-190.

Hayes, S. C., \& Wilson, K. G. (1993). Some applied implications of a contemporary behavior-analytic account of verbal events. The Behavior Analyst, 16, 283-301.

Hayes, S. C., \& Wilson, K. G. (1994). Acceptance and commitment therapy: Altering the verbal support for experiential avoidance. The Behavior Analyst, 17, 289-303.

McDowell, J. J. (1988). Matching theory in natural human environments. The Behavior Analyst, 11, 95-109.

Michael, J. (1980). Flight from behavior analysis: Presidential address ABA 1980. The Behavior Analyst, 3, $1-21$.

Michael, J. (1993). Establishing operations. The Behavior Analyst, 16, 191-206.

Schlinger, H., \& Blakely, E. (1987). Function-altering effects of contingency-specifying stimuli. The Behavior Analyst, 10, 41-45.

Van Houten, R., Axelrod, S., Bailey, J. S., Favell, J. E., Foxx, R. M., Iwata, B. A., \& Lovaas, O. I. (1988). The right to effective behavioral treatment. Journal of Applied Behavior Analysis, 21, 381-384.

"practitioner piece" (Van Houten et al., 1988), ${ }^{1}$ and even this one was more of a policy article. Although mixing rigorous research papers and timely practice pieces within the same journal may sound appealing at a conceptual level, in execution this simply did not work well over the long haul.

This could have happened for three reasons. First, the number of journals that publish behavior-analytic research has grown precipitously since $1978,{ }^{2}$ and as potential outlets for their work became more numerous, it is likely that authors often chose not to send their best work to a periodical that was as much a newsletter as a journal. For decades, The Behavior Analyst was ABAI's sole - and flagship - journal. But more differentiation within the field occurred, and as of 2017 ABAI now publishes four journals itself, each with its own mission (The Psychological Record: empirical articles; Behavior Analysis in Practice: practice pieces; The Analysis of Verbal Behavior: verbal behavior papers); notably, only one of these journals is practitioner oriented. Second, among the newer journals is Behavior Analysis in Practice, which is a natural

\footnotetext{
${ }^{1}$ It is readily recognized that citations are but one of many indices of an article or journal's impact and influence. It is also recognized that practitioners are less likely to cite influential and important articles in their work. However imperfect, citation data do provide some evidence of both readership and influence.

${ }^{2}$ Notable examples include The Psychological Record, The Analysis of Verbal Behavior, Behavior Analysis in Practice, Journal of Organizational Behavior Management, Journal of the Experimental Analysis of Behavior, Journal of Applied Behavior Analysis, Behavior Analysis: Research and Practice, Behavior and Philosophy, Behavioral Interventions, Behavioral Pharmacology, Behavioral Processes, Behavior Modification, Behavior and Social Issues, European Journal of Behavior Analysis, Experimental and Clinical Psychopharmacology, Japanese Journal of Behavior Analysis, Journal of Behavioral Education, Journal of Contextual Behavioral Science, Journal of Positive Behavior Interventions, Psychopharmacology, and Revista Mexicana de Análisis de la Conducta.
} 
home for the more practice-oriented pieces that The Behavior Analyst used to publish. Third, many new mechanisms have evolved for rapidly disseminating association news and business. For example, ABAI also now publishes a lengthy quarterly newsletter, and rapid electronic dissemination of news items is now the norm. The various and ubiquitous e-mail and social media platforms of today simply did not exist in 1978 .

All of these factors have led to two crucial questions regarding The Behavior Analyst: Is there a need for it to exist and, if so, what should the journal be? Function and form, once again.

\section{Mission Control}

The most persuasive reason for The Behavior Analyst to exist is ABAI's stated mission: "To contribute to the well-being of society by developing, enhancing, and supporting the growth and vitality of the science of behavior analysis through research, education, and practice" (https:/www.abainternational.org/about-us/strategic-plan.aspx). Behavior science is where we begin, and it is the adhesive for all that follows. Science thrives on publication and dissemination, and as a science organization committed to the whole of behavior analysis, ABAI should be publishing scientific journals. Moreover, because science is the centerpiece of the discipline, a strong and necessary statement about the association and its commitment to science is made by its flagship journal having a clear scholarly focus.

Most behavior analysis journals are primary empirical journals, and by their nature primary empirical journals are rather conservative in style. In hindsight, articles like those listed in Table 2 are memorable because they pushed the boundaries of behavioranalytic thinking. One need not agree with every point they make to appreciate that they nudged the field forward in interesting and useful ways. Also as illustrated by this table, the most impactful articles tend to address a wide range of topics and, in many cases, to take on issues that matter not only to behavior analysts but also to a wide variety of people in and out of the broader scientific community — as befits ABAI's mission. In works such as Science and Human Behavior, Skinner (1953) laid out a vision of a science that would be bold and unafraid to tackle whatever interesting topics the world could throw at it. ABAI's flagship journal should continue proudly in that tradition.

In 2015, we began efforts to align ABAI's flagship journal more closely with ABAI's scientific mission. Editorial processes were streamlined; article categories were simplified; and policy statements clarified the journal's primary focus on science, theory, and methodology (Hantula, 2016a, 2016b). We also adopted the publication strategy of "special-plus" issues; these issues feature a special section of thematically related papers, with some "regular" papers following. The scholarly community responded well to these changes. Submissions quadrupled, and the quality of the manuscripts has been very high. 


\section{What's in a Name?}

Policy changes were not enough to realize the vision of a flagship journal focusing on scholarly research. Such a journal has to be viewed as an authoritative scholarly source by both ABAI's members and those outside the organization. The moniker The Behavior Analyst brought its own separate issues that were caught up in history as well as changes in the environment. Language drives thought, as Skinner, Whorf, and others have observed, and "The Behavior Analyst" became part of a problematic equivalence class.

In particular, the journal's title, The Behavior Analyst, sounds more like a newsletter than a scholarly journal, which probably reflects its genesis. Many other scientific organizations use a similar title for their newsletters (e.g., The Industrial-Organizational Psychologist [SIOP], The Clinical Psychologist [APA Division 12], The Military Psychologist [APA Division19], The School Psychologist [APA Division 16]). Consequently, we have encountered resistance and trepidation from ABAI-invited lecturers who were asked to submit their talk to what they perceived as a newsletter. It is difficult to get submissions from scholars in behavior analysis and other disciplines whose home departments do not think that the journal is a legitimate scholarly outlet.

The article the in The Behavior Analyst is problematic for electronic searches. For example, searching for The Behavior Analyst in Journal Citation Reports yields nothing because it is indexed under Behavior Analyst (no article). This error occurs in article reference lists, too, and may also potentially contribute to lower impact ratings of the journal.

The journal's history of publishing a bit of everything has contributed to a low rate of citation, as many newsletter-style pieces, commentaries on practice issues, and association announcements tend not to be cited often. A low citation rate accentuates the impression of a weak journal and may further discourage submissions from scholars seeking a prestigious outlet. The days of "any publication is a good publication" are long gone. For instance, at many institutions, junior scholars who publish in lowranked journals are not given "credit" for those publications in annual recontracting and tenure reviews; in many cases, publishing research in such publications is seen as worse than not publishing at all. With full-time academic positions decreasing in number and becoming more difficult to obtain and to keep, junior scholars who want to be competitive must win grant money and publish in high-impact journals (which provide the evidence for further grant funding). The National Institutes of Health (NIH) now evaluates grant recipients partially on the basis of the "quality" of the journals in which their funded work is published.

Overall, the title The Behavior Analyst carries substantial historical baggage that works against the goal of establishing it as a serious scholarly journal. Renaming helps the journal to escape this past and start anew.

\section{Analyze This Equivalence Class}

In the somewhat repressed past when psychodynamic approaches dominated, the name analyst was shorthand for psychoanalyst (a practitioner of the Freudian or neo-Freudian arts). These individuals were often administrators and directors of mental health facilities and organizations, and their worldview ruled the day. The upstart operant 
conditioners had radically different ideas about the way the behavior of individuals in their care should be understood and changed. These "behavior modifiers" were a challenge to the orthodoxy. Many of these early behavioral practitioners also called themselves "analysts," co-opting the term as a tweak to the establishment, as in "You are a psychoanalyst _ I I am a behavior analyst." The psychodynamic approach is no longer dominant, and in a strange twist of fate, behaviorally oriented individuals now direct the very same institutions that were once solidly psychodynamic. That battle is over, and we should not be fighting last century's skirmishes; in many places now, behavior analysis is the establishment.

When The Behavior Analyst was founded in 1978, the term behavior analyst may have suggested scientist, researcher, or scholar. More recently, the term behavior analyst has become highly identified with the Behavior Analyst Certification Board and its certification processes, practitioners, and job titles. Yet the journal's content, which spans theoretical, philosophical, and methodological papers, has little to do directly with practice. ${ }^{3}$

In short, the title may be misleading. The Behavior Analyst does not run case reviews, functional analyses, or "10 tips" types of papers that are common in practice publications (authors have sent us all of these). With practice as the now-established frame of reference for a "behavior analyst", the journal's current title does little to telegraph its breadth. For example, recent issues include articles on philosophy, developmental systems, commitment, behavioral momentum, social referencing, incarceration, consumer behavior, the nature of reinforcement, public perception of behavioral terms, delay discounting methodology, and a review of a book on language written by a surgeon.

Beyond the mental health and education arenas, the term analyst itself is outdated. We have seen a transition in the quantitative world from data analysts to data scientists. The reasons for the transition are many but can be summarized as follows. Analysts are more narrowly trained technicians with a limited set of skills who are focused less on contributing to a knowledge base. By contrast, scientists are broadly trained and possess a wider range of technical skills along with theoretical and philosophical grounding, which allows them to contribute to a scientific knowledge base. More practically, scientists solve problems and make discoveries; analysts merely make recommendations. Hence, behavior analyst in the title of a research-based scholarly journal is doubly dated.

\section{To the Future}

The world's largest organization for behavioral scientists deserves a first-rate scholarly flagship publication. We hope that ABAI's "new" flagship journal will be both strange and

\footnotetext{
${ }^{3}$ The BCBA certification process cannot confer the title of behavior analyst to individuals whose work is solely that of scientist, researcher, or scholar. As the BACB pushes for licensure, this issue may become critical. For a small $N$ example, although we each hold a $\mathrm{PhD}$ in psychology and a faculty position in a department of psychology, none of us can be referred to as a psychologist because none of us is a licensed clinical, counseling, or school psychologist. This could be the case as well for behavior analyst in the near future. The American Psychological Society sidestepped this issue by referring to its members as "psychological scientists." Perhaps scholarly ABAI members will need to start referring to themselves as "behavioral scientists."
} 
familiar to anyone taking a 1978 perspective - strange in how much it omits, but familiar in echoing the spirit of those most cited articles of the past (as shown in Table 2).

An irony that strikes us every June is that so few of the fascinating bar and social conversations that characterize ABAI conferences in May seem to make it into our field's journals. ABAI's flagship journal should be as adventurous as those conversations. It should provide a forum in which authors can take intellectual risks and, when necessary, explore what results from disrupting the status quo. In rebranding and refocusing the journal, we seek to establish an environment in which smart people, whether members of ABAI or not, have relative freedom to say intelligent things about behavior. We try not to be the thought police and to stay out of the way of an author who can string together a coherent argument for an interesting idea, regardless of whether that idea defends or challenges the status quo. Because we well understand how delay degrades reinforcement, we try to provide rapid feedback (for the most recent volume year, initial manuscript decisions were sent to authors an average of 30 days after submission) and try to make feedback easy to digest and focused on improving, rather than micromanaging, the message.

For the "new" journal, we plan to have a more frequent publication schedule and more diverse coverage of science, theory, and methodology. We will continue the "special-plus" publication strategy. Each issue will feature a thematic special section supplemented by other research articles, book reviews, and "In Memoriam" pieces. To make this work, of course, we need your assistance: We welcome your paper submissions, ideas, and proposals for special sections or special issues that address important issues in behavioral science, writ large.

\section{References}

Hantula, D. A. (2016a). Editorial: a very special issue. The Behavior Analyst, 39, 1-5. https://doi.org/10.1007 /s40614-016-0066-5.

Hantula, D. A. (2016b). Expanding the scope: beyond the familiar and beyond the page. The Behavior Analyst, 39, 189-196. https://doi.org/10.1007/s40614-016-0078-1.

Marr, M. J. (1991). The speciation of behavior analysis: the unnatural selection of foxes and hedgehogs. The Behavior Analyst, 14, 183-186.

Marr, M. J. (2017). The future of behavior analysis: foxes and hedgehogs revisited. The Behavior Analyst, 40, 197-207. https://doi.org/10.1007/s40614-017-0107-8.

Pierce, W. D., \& Epling, W. F. (1980). What happened to analysis in applied behavior analysis? The Behavior Analyst, 3, 1-9.

Rider, D. P. (1991). The speciation of behavior analysis. The Behavior Analyst, 14, 171-181.

Skinner, B. F. (1953). Science and human behavior. New York: MacMillan.

Wood, W. S. (1978). Editorial. The Behavior Analyst, 1, 1-2. 